\title{
Interpretasi Sufistik Hadis (Telaah Pemikiran Jalaluddin Rumi dalam Kitab Fihi Mā Fihi)
}

\author{
Oga Satria \\ Pascasarjana (UIN) Syarif Hidayatullah \\ satriaoga@rocketmail.com
}

\section{ABSTRACT}

The purpose of this paper is to explore the interpretation of hadith by Jalaluddin Rumi in the fibi ma fihi book. As one method of interpretation of religious text contained in Islam, Sufistic interpretation is considered tendly to see the meaning of the hadith text in accordance with the sufi intuition that comes from purity of the heart rather than fixated on textual meaning. Therefore, the meaning of a hadith produced by sufi is sometimes seen to be distorted and far from its textual meaning. This study uses qualitative descriptive analytative method that aim to describe or provide an overview of the object under study through the data that has been collected and then conduct analysis and draw the conclusion from the problem. This research proves that the hadith interpretation by sufi, especially Jalaluddin Rumi, does not always contradict with the meaning of hadith textuality. Rumi on several occasions even interpreted the hadith textually as interpreted and understood by the other scholars of hadith.

Keywords: Jalaluddin Rumi, Sufistic Interpretation, Textual

\begin{abstract}
ABSTRAK
Tulisan ini bertujuan untuk mengeksplorasi interpretasi hadis yang dilakukan oleh Jalaluddin Rumi di dalam kitab fihi ma fihi. Sebagai salah satu metode interpretasi teks keagamaan yang terdapat di dalam Islam, interpretasi sufistik dianggap cenderung melihat makna teks hadis sesuai dengan intuisi sang sufi yang berasal dari kesucian hati bukan terpaku pada makna tekstual. Oleh karena itu, pemaknaan terhadap sebuah hadis yang dihasilkan oleh para sufi terkadang terlihat menyimpang dan jauh dari makna tekstualnya. Penelitian ini menggunakan metode kualitatif deskriptif analitis yang bertujuan untuk mendeskripsikan atau memberikan gambaran terhadap objek yang diteliti melalui data yang telah terkumpul dan kemudian melakukan analisis serta menarik kesimpulan dari permasalahan tersebut. Penelitian ini membuktikan bahwa interpretasi hadis yang dilakukan oleh seorang sufi, terutama Jalaluddin Rumi, tidak selamanya bertentangan dengan makna tekstualitas hadis. Rumi dalam beberapa kesempatan bahkan memaknai hadis secara tekstual sebagaimana yang ditafsirkan dan dipahami oleh ulama-ulama hadis lainnya.
\end{abstract}

Kata kunci: Jalaluddin Rumi, Interpretasi Sufistik, Tekstual 


\section{PENDAHULUAN}

Interpretasi sufistik merupakan salah satu bagian dari metode penafsiran yang ada di alam Islam. Metode tersebut lebih banyak dipengaruhi oleh aliran tasawuf, sehingga cenderung menggunakan intuisi yang berasal dari hati yang bersih dalam melakukan penafsiran. Selain itu, penafsiran sufistik juga lebih banyak menekankan pada aspek etika dan berorientasi kepada penyucian jiwa serta memberi sifat zuhud dengan lebih memprioritaskan kehidupan akhirat dibandingkan dengan dunia. Penafsiran dengan metode ini dibenarkan oleh Ibn Qayyim, sebagaimana dikutip oleh Manna al-Qattan, mengatakan bahwa terdapat beberapa persyarat agar metode tafisr tersebut dapat diterima, yaitu tidak bertentangan dengan makna lahir (pengertian tekstualnya), didukung atau diperkuat dengan dalil-dalil syar'i lainnya, tidak bertentangan dengan dalil syara' atau rasio, tidak menganggap kemutlakan penafsiran, dan penafsirannya tidak terlalu jauh dari teks, sehingga masih dapat dilihat korelasinya (Manna al-Qattan, 2000, h. 347-348).

Penafsiran yang dilakukan oleh seorang sufi sering terlihat bertentangan dengan tekstual hadis, sehingga mereka terkesan memaknai suatu hadis terlalu jauh dari makna yang diinginkan. Akan tetapi, salah seorang sufi besar, Jalaluddin Rumi, tidak selalu memaknai hadis berbeda dengan tekstual hadis yang ia kutip di dalam kitab fibi ma fibi. Oleh karena itu, penting untuk melihat lebih jauh interpretasi teks hadis yang dilakukan oleh Jaluluddin Rumi karena kebanyakan penelitian yang meneliti tentang sosok Jalaluddin Rumi cenderung hanya melihat makna-makna dari syair ataupun konsep tasawufnya saja tanpa melihat bagaimana upaya Rumi dalam melakukan interpretasi terhadap teks hadis yang menjadi landasan argumennya. 
Hal ini terlihat dari beberapa penelitian seperti tulisan Ihsan Yilmaz (2009) yang menyorot konsep Islam dan Islamisme dengan menjadikan kebiasan sehari-hari Rumi sebagai contoh kasusnya. Selain itu, Eni Murdiati (2011) juga menulis tentang Jalaluddin Rumi, akan tetapi ia melihat tarian Rumi. Ahmad Murad Merican (2012) juga menulis penelitian tentang Jalaluddin Rumi yang berjudul "Rumi and The Advancement of Man and Society." Dia lebih banyak melihat Rumi sebagai sosok storytaller tentang kaitan antara manusia dan masyarakat ataupun alam semesta. Kemudian penelitian Farah Iqbal, dkk. (2015) dengan tema "Understanding Emphaty with Reference to Rumi" juga menyorot tentang sisi empati ari filosofi hidup Jalaluddin Rumi.

\section{HASIL DAN PEMBAHASAN}

\section{Definisi Interpretasi Sufistik}

Pemahaman hadis (figh al-Hadis) merupakan salah satu instrumen penting dalam kajian hadis. Istilah tersebut terdiri dari dua kata, yaitu figh dan al-Hadis. Secara etimologi, kata figh dapat diartikan dengan mengerti atau memahami (Ahmad Warson Munawwir, 1997, h. 1067) atau juga dapat diartikan dengan pengetahuan, pengertian, dan pemahaman (Ibn Manzhur, 1994, h. 3450). Adapun secara terminologi, fiqh adalah sebuah ilmu yang berkaitan dengan hukum-hukum shara' yang diperoleh dari dalil-dalil yang terperinci (Zakariyya ibn Muhammad al-Ansari, 1998, h. 8). Sedangkan kata al-Hadis secara etimologi diartikan dengan baru atau berita dan secara terminologis, al-Hadis adalah segala sesuatu yang diriwayatkan dari Nabi Muhammad setelah kenabian, baik itu berupa perkataan, perkataan, maupun ketetapan dari beliau ('Ajjaj al-Khatib, 2009, h. 19). Jadi, fiqh al-Hadis dapat didefinisikan sebagai salah satu aspek ilmu yang berkaitan dengan upaya untuk memahami hadis-hadis Nabi dengan baik.

Metode interpretas teks keagamaan (al-Qur'an dan Hadis) dalam Islam tidak hanya menggunakan sebuah teks untuk menginterpretasi teks lain (nalar naq) atau menggunakan akal untuk menggali makna teks (nalar 'aqli), akan 
tetapi juga menggunakan kesucian batin (nalar irfani). Stephen T. Katz beranggapan bahwa sufistik ataupun mistisime secara umum juga telah diakui benar adanya oleh masyarakat luas (Steven T. Ketz, 2000). Metode penafsiran ini tidak hanya melihat teks sebagaimana yang tertulis di dalam al-Qur'an dan Hadis, akan tetapi mencoba menangkap isyarat-isyarat halus yang tersimpan di balik teks dan hal tersebut hanya mampu disingkap oleh kesucian dan kejernihan hati.

Metode interpretasi sufistik terhadap teks al-Qur'an dan Hadis yang dilakukan oleh para sufi memiliki kesamaan, yaitu berdasarkan isyarat-isyarat rahasia yang hanya mampu dilihat oleh para ahli tasawuf, atau dengan kata lain, penafsiran tersebut memadukan antara makna tersirat dengan makna yang tersurat (Muhammad Husain al-Zahabi, t.th, h. 352). Metode ini muncul karena anggapan para sufi bahwa setiap ayat dan hadis mempunyai makna zahir dan batin. Jika makna zahir dapat ditangkap dengan mudah oleh akal pikiran, maka makna batin membutuhkan usaha untuk memahami isyaratisyarat yang tersembunyi. Oleh karena itu, untuk memperoleh kemampuan memahami isyarat-isyarat tersebut dibutuhkan latihan kerohanian sehingga mencapai pada tingkatan di mana akan terungkap pada dirinya berbagai isyarat suci dari balik tabir. Menurut para sufi, kamampuan untuk memahami makna teks tidak dianugerahkan kepada semua orang biasa, akan tetapi diterima oleh orang yang sadar, berpengetahuan, memiliki akhlak yang terpuji dan mampu melawan hawa nafsu mereka. Kemampuan ini muncul dari ilham yang diberikan oleh Allah dengan cara memasukkan ide-ide ke dalam hati hamba-Nya yang ikhlas (H Thameem Ushama, 2000, h. 24).

Thameem Ushama lebih lanjut mengatakan bahwa interpretasi sufistik tersebut dapat diterima selama terbebas dari beberapa hal, antara lain inkonsistensi dan kontradiksi dengan makna lahir teks, tuduhan dan anggapan bahwa tujuan dan maknanya unik tanpa memandang kepada makna lahir, mengabaikan dan tidak menerima ta'wil, kontradiksi dan konflik dengan 
aspek-aspek hukum dan pemikiran yang sudah baku, dan terhindar penafsiran yang akan membingungkan orang lain yang membacanya $(\mathrm{H}$ Thameem Ushama, 2000, h.28-29).

\section{Otentisitas Hadis di Kalangan Ahli Hadis dan Sufi}

Kaidah otentisitas hadis Nabi hingga ia dapat diterima di kalangan ulama hadis, maka ia harus mencangkup empat hal. Pertama, ittisal al-sanad, yaitu adanya keterikatan atau ketersambungan sanad antara satu perawi dengan perawi yang lain. Nur al-Din 'Itr memaknai ittisal al-sanad dengan mengatakan bahwa setiap perawi hadis benar-benar menerima riwayat hadis tersebut dari perawi sebelumnya dan begitu seterusnya hingga sampai kepada pembawa yang pertama (Nur al-Din 'Itr, 1979, h. 242). Mahmud Tahan juga memberikan makna ittisal al-sanad dengan proses pengambilan hadis oleh seorang perawi secara langsung dari perawi yang berada di atasnya (perawi sebelumnya), dari awal sanad hingga akhir sanad (Mahmud Tahan, t.th, h. $31)$.

Lebih lanjut imam Bukhari mensyaratkan dalam ittisal al-sanad harus terjadinya pertemuan antara satu perawi dengan perawi lainnya (liqa') meskipun mereka hanya bertemu satu kali. Berbeda dengan Bukhari, Imam Muslim dalam melihat ittisal al-sanad antara satu orang perawi dengan perawi lainnya lebih sedikit longgar. Dia hanya mensyaratkan adanya kemungkinan terjadinya pertemuan antara satu perawi dengan perawi lainnya yang ditandai dengan masa hidup mereka dalam kurun waktu yang sama (mu'asarah) dan juga mereka tinggal di daerah yang berdekatan meskipun mereka belum pernah bertemu sama sekali (Ibnu Hajar, 1991, h. 12. Lihat juga Mahmud Mahmud bin Ahmad al-'Ayni, t.th, h. 5).

Kedua, perawi hadis harus orang yang bersifat adil. 'Ajjaj al-Khatib mengatakan bahwa maksud dari perawi yang adil adalah perawi yang memiliki agama yang lurus, tidak menyekutukan Tuhan. Selain itu, dia juga memiliki akhlak yang baik dan terhindar dari kefasikan serta hal-hal yang dapat 
menjatuhkan muru'ab nya. Sedangkan Mahmud Tahan mendefinisikan perawi yang adil dengan perawi yang berstatus muslim, sudah mencapai usia baligh, berakal, tidak fasik, dan tidak memiliki akhlak yang buruk (Mahmud Tahan, t.th, h. 31). Tidak hanya spesifikasi sebelumnya saja yang membuat perawi digolongkan menjadi perawi yang adil, akan tetapi menurut imam al-Hakim, ia juga harus menjadi seorang hafiz, yaitu keadaan di mana seorang perawi tidak boleh lupa ketika menyampaikan atau meriwayatkan hadis dari kitab asalnya (Abu 'Amru al-Hakim, 1977, h. 53). Menurut penulis kriteria tersebut lebih cocok apabila dikaitkan dengan status ke-dabit-an seorang perawi dibandingkan dengan status keadilan.

'Ajjaj al-Khatib menjelaskan cara mengetahui keadilan seorang perawi, antara lain melalui pernyataan dari seseorang yang sudah terkenal keadilannya. Selian itu, keadilan seorang perawi juga dapat diketahui melalui kemasyhuran rawi itu sendiri dengan sifat yang telah ia miliki, seperti Malik bin Anas, al-Shafici, Ahmad bin Hanbal, dan lain sebagainya. Khusus untukl para sahabat, ulama sudah bersepakat tentang sifat keadilan yang melekat kepada diri mereka. Hal tersebut berdasarkan nas yang terdapat di dalam alQur'an dan Hadis ('Ajjaj al-Khatib, 2009, h. 201).

Ketiga, perawi juga harus berstatus dabit. Dabit merupakan kesadaran seorang perawi ketika menerima hadis, paham ketika mendengarkan dan menghafalnya sejak ia menerima hadis tersebut sampai menyampaikan atau meriwayatkan kepada orang lain ('Ajjaj al-Khatib, 2009, h. 201). Sedangkan menurut Mahmud Tahan, dabit merupakan perawi yang memiliki daya ingat yang sempurna, baik itu melalui ingatan maupun berupa catatan yang ia tulis (Mahmud Tahan, t.th, h. 31). Apabila di dalam diri seorang rawi telah terkumpul sifat adil dan dabit, maka ia pantas untuk menyandang gelar siqah (terpercaya).

Keempat, terhindar dari kejanggalan ('Adam al-Syuzu₹). Mahmud Tahan mengartikan syaz dengan hadis yang tidak menyelisihi riwayat perawi lain 
yang lebih siqah dibandingankan dirinya (Mahmud Tahan, t.th, h. 31). Sedangkan imam al-Hakim mendefinisikan syaz dengan sebuah hadis yang diriwayatkan oleh perawi yang siqah, akan tetapi tidak ada perawi siqah lainnya yang meriwayatkan hadis tersebut atau dengan kata lain, seorang perawi yang siqah menyendiri dalam hal periwayatan hadis (Abu 'Amru al-Hakim, 1977, h. $53)$.

Kelima, terhindat dari 'illat. Dalam ilmu hadis, 'illat diartikan dengan suatu tindakan yang dapat mencacatkan seorang perawi, seperti memursalkan hadis yang maushul, memuttashilkan hadis yang munqathi ataupun memarfu'kan hadis yang mauquf, dan lain sebagainya ('Ajjaj al-Khatib, 2009, h. 201). Mahmud Tahan mengatakan bahwa yang dimaksud dengan tidak berillat adalah terhindar dari kecacatan. 'Illat merupakan penyebab tersembunyi yang dapat mencaemari ke-sabib-an sebuah hadis, meskipun secara zahir hadis tersebut tidak memiliki kecacatan atau masalah (Mahmud Tahan, t.th, h. 31).

Berbeda dengan kalangan ulama hadis dalam menentukan otentisitas hadis Nabi, kaum sufi tidak hanya terpaku kepada penelitian terhadap sanad dan matan hadis, akan tetapi harus sejalan dengan al-Qur'an dan diriwayatkan oleh seorang perawi yang mempunyai tingkat kesalehan yang tinggi. Meskipun pada ulama tasawuf mengakui kriteria yang digunakan oleh ulama hadis, akan tetapi bagi kaum sufi terdapat dua metode utama yang digunakan untuk menentukan keotentikan suatu hadis, yaitu dengan liqa' al-Nabi dan tariq al-Kasyaf. Metode liqa' al-Nabi dimaknai dengan perjumpaan dengan Nabi Muhammad saw sebagai sumber hadis, baik peristiwa itu terjadi ketika bermimpi maupun ketika bercakap langsung dengan Nabi dalam keadaan terjaga (Usman Sya'roni, 2008, h. 50). Hal tersebut tanpak irrasional bagi orang-orang yang tidak pernah memasuki dunia tasawuf atau bahkan bertentangan dengan akidah mengingat Nabi sudah lama wafat. Akan tetapi, 
bagi kaum sufi, hal tersebut dapat benar-benar terjadi (Abu Muhammad alWalatturi, 1997, h. 57).

Metode kedua yang digunakan para sufi adalah tariq al-Kasyaf. Dalam dunia tasawuf, kasyaf adalah menyingkap penghalang atau hijab dari rahasiarahasia gaib, persoalan-pesoalan haqiqiyyah, wujud, dan syubud ('Abd al-Mun'im al-Hafani, 1987, h. 225). Sedangkan dalam pandangan Ibn 'Arabi, kasyaf merupakan penyingkapan tabir dari pengetahuan potensial dan pengunggahan kesadaran suci yang terdapat di dalam hati manusia (A. E. Afifi, 1995, h. 151). Kondisi tersebut memungkinkan seseorang untuk bertemu dengan Nabi secara sadar untuk berdiskusi tertang permasalah hukum, tafsir al-Qur'an, status hadis, dan lain sebagainya. Hal ini pula yang membuat para sufi dapat menerima hadis tanpa mengikuti kriteria yang telah ditetapkan oleh para ulama hadis, seperti kebutuhan terhadap bersambungnya sanad untuk menentukan ke-sabih-an sebuah hadis. Metode tersebut banyak digunakan oleh para sufi, seperti Ibn 'Arabi, al-Ghazali, Abu al-'Abbas al-Tijani>, Sheikh 'Abd al-Qadir al-Shadhili, dan lain sebaginya (Muhammad Adam Abd. Azid dan Khadher Ahmad, 2017, h. 95-96).

Sedangkan dari sisi metode penafsiran terhadap teks keagamaan, baik al-Qur'an ataupun Hadis, para sufi juga memiliki perbedaan dengan para ulama hadis pada umumnya. Yusuf al-Qardawi sebagai salah satu representasi dari ulama hadis mengatakan bahwa terdapat cara dalam memahami hadis Nabi, yaitu memahami hadis sesuai petunjuk al-Qur'an, menghimpun hadishadis yang setema, menggabungkan atau mentarjih hadis-hadis yang bertentangan, memahami hadis sesuai latar belakang, situasi, kondisi, dan tujuan, membedakan antara sarana yang berubah dan tujuan yang tetap, membedakan antara ungkapan yang haqiqah dan majaz, membedakan yang ghaib dan yang nyata, dan memastikan makna kata-kata dalam hadis (Yusuf al-Qardawi, 1991, h. 93). 
Berbeda dengan metode interpretasi oleh ulama hadis, seperti Yusuf alQardawi tersebut, metode interpretasi sufistik lebih menekankan kepada aspek etika, berorientasi kepada aspek penyucian jiwa atau mhaniyah, serta memiliki pandangan hidup yang lebih memprioritaskan kepada kehidupan akhirat dibandingkan dengan keduniawian. Metode tersebut tidak melihat kepada makna teks secara dzahir, akan tetapi lebih cenderung melihat kepada makna batiniyah yang terkandung di dalam teks (Manna al-Qattan, 2000, h. 346-347). Al-Zarqani mendefinisikan tafsir isyari atau sufistik dengan sebuah metode tafsir berdasarkan isyarat atau indikator yang terdapat dibalik dzahir teks berdasarkan pengalaman yang diperoleh oleh para ahli suluk (Muhammad 'Abd al-'Azim al-Zarqani, t.th, h. 78). Mereka tidak terlalu banyak menempuh cara-cara khusus untuk memahami hadis sebagaimana yang dilakukan oleh para ulama hadis karena mereka lebih dominan menggunakan hati atau intuisi dalam memahami hadis Nabi.

\section{Biografi Jalaluddin Rumi}

Nama lengkapnya adalah Muhammad Jalal al-Din Muhammad bin Muhammad al-Balkhi al-Qounawy (Qonya, dahulu masuk wilayah Anatolia, Romawi, sekarang menjadi bagian dari Negara Turki). Namun ada juga yang menyebut nama lengkap dari Jalaluddin Rumi adalah Muhammad bin Husain al-Khatibi al-Bahri. Nama al-Rumi yang dinisbatkan kepadanya dikarenakan dia menjadi salah seorang ahli tasawuf dan penyair sufi terkenal yang menghabiskan sebagian besar hidupnya di daerah Konia, Turki, yang dilu merupakan bagian dari kerajaan Romawi Timur. Rumi lahir di kota Balkh (yang sekarang dikenal dengan Afghanistan), sebuah kota kuno atau tua yang dahulu menjadi pusat perkembangan agama Zoroaster, pada tahun $604 \mathrm{H} /$ 1207 M (Annemarie Schimmel, 1993, h. 15). Pada masa itu, wilayah tersebut merupakan bagian wilayah yang dikuasai oleh kerajaan Khwarizmi yang beribukota di Bukhara, Transaksonia. 
Rumi wafat pada tahun $672 \mathrm{H} / 1273 \mathrm{M}$. Ayahnya adalah Muhammad bin Husain al-Khatibi atau yang lebih dikenal juga sebagai Bahauddin Walad yang memiliki garis keturunan (nasab) dari Abu Bakr al-Siddiq. Dia merupakan salah satu ulama terkemuka dari Balkh dalam bidang keilmuan Islam, seperti fiqh, ilmu kalam, tasawuf, dan lain sebagainya, sehingga ia memperoleh gelar sultan al-ulama (Muhammad 'Abd al-Salam Kafafi, 1966, juz 1, h. 2). Pada tahun $1210 \mathrm{M}$, sebelum negeri ini diserbu oleh tentara Genghis Khan, sehingga Bahauddin Walad beserta keluarganya harus hijrah meninggalkan Balkh tanpa alasan yang jelas. Ada yang berpendapat bahwa hal tersebut disebabkan oleh persoalan politik. Raja Khwarizmi pada masa itu, Muh\}ammad Khwarizmiyah, menentang keberadaan tarikat Kubrawiyah yang dipimpin oleh ayah Rumi. Namun, ada juga yang berpendapat bahwa hijrahnya Bahauddin Walad dan keluarga disebabkan oleh kekhawatiran terhadap serbuan tentara Mongol yang ketika itu telah menghampiri wilayah Khawarizmi (Tah\}sin 'Abd al-Jabbar Isma>'il, 2013, h. 17). Namun, pendapat yang kedua dianggap lemah, karena pada tahun 1210 M, kelompok Genghis Khan masih tidak dapat menaklukkan bagian utara dari negeri Cina yang juga merupakan jembatan menuju Asia Tengah.

Sebelum menjalani kehidupannya sebagai seorang sufi secara penuh, Jalaluddin Rumi belajar berbagai macam ilmu keislaman, seperti fikih, ilmu kalam, bahasa Arab dan gramatikanya kepada ayahnya sendiri, Bahauddin Walad. Bahkan ia menjadi penerus ayahnya dalam memberi ceramah dan mengajar kepada para jamaah. Tak lama kemudian, Burhan al-Din alTirmidzi, yang merupakan murid dari ayah Jalaluddin Rumi, datang ke Konya dan menggantikan peran Bahauddin Walad sebagai pengajar di sana, termasuk mengajari Jaluddin Rumi. Dia sekaligus menjadi guru spiritual pertama bagi Jalaluddin Rumi. Burhan al-Din al-Tirmidzi memberi nasehat kepada Jalaluddin Rumi untuk hijrah ke Syam demi mendalami ilmu agama. Akhirnya pada tahun $630 \mathrm{H}$ Jalaluddin Rumi berangkat ke kota Syam, 
tepatnya di daerah Aleppo $(H\{a l b)$. Di sini dia mendalami ilmu fikih madzhab Hanafi dan ilmu lainnya kepada Syeikh Kamaluddin Abi al-Qasim Amr bin Ahmad di madrasah al-Halawiyyah. Namun, proses menuntut ilmu yang dilakukan oleh Rumi di sini tidak bertahan begitu lama. Dia kemudian kembali ke Konya ntuk kembali mengajar. Akan tetapi, sekembalinya ke Konya, Rumi juga aktif memberi fatwa terkait permasalah yang sedang di hadapi pada saat itu (Abu al-Hasan al-Nadwi, 2018, h. 13).

Peristiwa penting yang membuat Jalaluddin Rumi menjadi salah seorang dari sufi terkenal dan mengubah total hidupnya adalah pada saat perjumpaannya dengan Darwis agung yang berasal dari Tabriz (ibukota Daulah Ilkhan Mongol di Persia pada mas itu), yaitu Muhammad bin 'Ali bin Malik Dawud, atau lebih dikenal dengan nama Shams Tibrizi pada tahun 642 H. Shams Tibrizi merupakan salah seorang pemimpin tasawuf yang suka mengembara dari satu derah ke daerah lain, tanpa memikirkan harta dan keselamatan jiwanya. Dia tidak pernah merasa khawatir dengan kondisi peperangan yang terjadi ketika di dalam masa pengembaraannya. Dia memberi banyak pengajaran kepada orang-orang Islam yang sedang berputus asa dan kebingungan karena penjarahan yang dilakukan oleh tentara Mongol dan Salib. Dia memberi pengetahuan tentang kekuatan cinta Ilahi dalam mengubah nasib manusia. selain itu, dia juga memberi nasihat agar umat Islam terlepas dari kebodohan-kebodohan yang terdapat di dalam diri mereka yang disebabkan oleh ajaran Jabbariyah dan paham taklid (Rein old A. Nicholson, 2017, h. 14).

Terdapat banyak riwayat yang menceritakan tentang perjumpaan antara jalaluddin Rumi dengan Shams Tibrizi. Salah satunya adalah riwayat dari Abu al-Hasan al-Nadwi yang menceritakan bahwa pada suatu hari, Rumi sedang menunggangi binatang kendaraannya dengan diiringi para murid dan pengikutnya. Di dalam perjalanan, banyak masyarakat yang bertanya terkait berbagai persoalan keagamaan kepada Jalaluddin Rumi. Kemudian tiba-tiba 
Syams Tibrizi menghampiri dan mengajukan pertanyaan; "apa maksud dari melakukan riyadah dan ilmu?",Rumi kemudian menjawab; “mengkaji aturanaturan syariat". Kemudian dengan tenang dan penuh percaya diri Syams kembali memberikan argumen; "bukan itu, tetapi mencapai pada yang Maklum (Yang Maha Diketahui), lalu Syams mendendangkan sebuah syair seorang sufi bernama al-Sinai "jika ilmu tidak dapat membuatmu melepaskan diri dari nafsu, maka tidak berilmu akan lebih baik darinya" (Abu al-Hasan alNadwi, 2018, h. 13).

Namun, ada juga yang menyebutkan bahwa ketertarikan Jalaluddin Rumi terhadap Shams Tibrizi disebabakan oleh khutbah-khutbah yang ia sampaikan sangat memikat penduduk negeri. Selain itu, kepribadiannya juga memberikan kesan yang mendalam dalam diri Jalaluddin Rumi (Rein old A. Nicholson, 2017, h. 14). Shams tidak tinggal di asrama-asrama khusus, yang disebut dengan istilah zawiyah atau tikyah, sebagaimana yang biasanya dilakukan oleh sufi kebanyakan pada masa itu. Begitu juga dengan pakaian yang digunakan oleh Shams. Akan tetapi, Rumi lebih tertarik ketika melihat pemikiran Shams terutama terkait keyakinan beragamanya.

Semenjak saat itu, Rumi tidak mau berpisah dari gurunya dan bahkan aktivitas mengajar dan pertemuan Rumi dengan para muridnya mulai terganggu. Hingga suatu ketika Shams Tibriz diusir oleh ratusan murid Rumi yang tidak menyukai kehadirannya di Konya dan memaksanya berpindah ke tempat lain. Semenjak kepergiannya, Rumi beberapa kali mengirim surat kepada Shams Tibriz untuk membujuknya kembali ke Konya, tetapi tidak pernah berhasil. Hingga akhirnya Rumi mengutus putranya, Sultan Walad untuk menemuinya di Syam dan berhasil membawanya kembali ke Konya. Tidak berselang berapa lama, terjadi lagi fitnah lagi yang menimpa Shams untuk yang kedua kalinya karena sudah membuat Rumi menjadi orang "gila". Sehingga sebagian dari mereka bersepakat bahwa halalnya darah Shams dan dibolehkan membunuhnya ('Isa 'Ali al-'Akub, 2002, h. 15-16). 


\section{Pemahaman Hadis Jalaluddin Rumi di dalam Kitab Fihi ma Fihi}

Terdapat beberapa hadis yang digunakan oleh Jalaluddin Rumi di dalam kitab fibi ma fibi untuk menguatkan argumennya dalam menjelaskan berbagai persoalan terutama yang berkaitan dengan pendidikan ruhani. Di antara persoalan yang dibahasa oleh Rumi di dalam kitab tersebut antara lain:

\section{Kuasa Allah dalam setiap peristiwa}

Di dalam pembahasan tersebut, Rumi mengutip perkataan Nabi:

$$
\text { اللهم اراني الأشياء كما هي }
$$

"Ya Tuban, perlibatkanlah kepadaku segala sesuatu sebagaimana adanya."

Setelah meneliti tentang kualitas hadis tersebut, penulis tidak menemukan adanya riwayat yang menyatakan demikian. Akan tetapi, Ibn alJauzi mengatakan bahwa ungkapan tersebut merupakan atsar. Atsar menurut para ulama merupakan sinonim dari kata hadis. Keduanya digunakan untuk menyebutkan yang marfu', manquf, dan maqt\}u'. Kadang-kadang ahli hadis menyebutkan yang marfu' dan mauquf termasuk atsar, akan tetapi bagi kalangan fiqh Khurasan menyebut mauquf dengan athar dan marfu' dengan khabar. Atau dengan kata lain, hadis merupakan sebutan untuk segala sesuatu yang datang dari Nabi, sedangkan khabar atau athar digunakan untuk menyebutkan segala sesuatu yang datang dari selain Nabi, seperti sahabat, tabiin, dan lain sebagainya. ('Ajjaj al-Khatib, 2009, h. 19-20).

Al-Mula 'Ali al-Qari juga mengatakan bahwa ungkapan tersebut bukanlah hadis nabi, akan tetapi salah satu ungkapan yang terkenal dikalangan para sufi (Nur al-Din 'Ali, 1987, h. 290). Dalam pandangan ulama hadis, penggunaan hadis yang tidak sahih atau bahkan hadis maudu' sering kali dilakukan oleh para sufi. Hal tersebut disebabkan oleh metode dalam penetapan ke-s\}ab\}ib\}-an yang berbeda di antara kedua kelompok tersebut. Abu 'Ubaidah al-Sidawi juga menyatakan bahwa kelompok sufi tidak terikat dengan standar keotentikan hadis yang telah ditetapkan oleh ulama hadis, 
sehingga dalam prakteknya banyak hadis yang diklam sahih oleh sebagian ahli sufi, ternyata bagian dari hadis palsu menurut jumhur ulama hadis. Bahkan para sufi mengatakan bahwasanya sumber hadis yang mereka terima bukanlah dari orang yang mati, akan tetapi mereka mengambil hadis dari Yang Maha Hidup dan tidak akan pernah mati, yaitu hati atau Tuhan (Ikhwan Fauzi Rizal, 1996, h. 86).

Meskipun dalam pandangan ulama hadis dalil tersebut bukanlah merupakan hadis Nabi, akan tetapi dalam pandangan Rumi ungkapan tersebut merupakan hadis Nabi yang menceritakan sebuah peringatan kepada manusia untuk selalu tunduk dan merendahkan diri di hadapan Allah. Ketika kita terlalu percaya pada diri sendiri dan lupa kepada Allah Yang Maha Benar, maka kita tidak akan dapat melihat bahwa segala sesuatu berasal dari Yang Maha Benar. Segala sesuatu di dunia ini tidak selalu tampak secara hakiki. Terkadang Allah memperlihatkan sesuatu yang baik (dari sudut pandang manusia), akan tetapi di dalamnya terdapat berbagai macam keburukan (Jalal al-Din Rumi, 2016, h. 33-34).

Hal tersebut disebabkan oleh persepsi dan pikiran manusia secara murni tidak akan memastikan kebenaran. Oleh karena itu, kesadaran semacam ini harus selalu ditanamkan dalam diri setia hamba agar tidak mudah tertipu dan menganggap bahwa setiap perbuatan baik ataupun kebenaran berasal dari dirinya sendiri. Jika manusia sudah menganggap bahwa kebaikan dan kebenaran datang dari dalam dirinya, maka dia memiliki potensi untuk terjatuh kedalam kemaksiatan. Interpretasi yang dilakukan Rumi tersebut memang lebih banyak memiliki muatan etika sebagaimana orientasi tasawuf sendiri yaitu untuk penyucian jiwa. Sedangkan ulama hadis tidak banyak memberikan komentar seputar penafsiran dari ungkapan tersebut, mereka lebih banyak menjelaskan dari sisi kualitas. 


\section{Melebur dalam cahaya Allah}

Salah satu jalan untuk mendekatkan diri kepada Allah adalah melalui shalat. Akan tetapi, shalat yang dimaksud di sini bukanlah sholat yang hanya sebatas gerakan fisik. Menurut Rumi, fisik itu hanyalah sebuah kemasan. Untuk memperkuat argumennya, Rumi mengutip sebuah ungkapan dari Nabi:

$$
\text { لي مع الله وقت لا يسع فيه ملك مقرب ولا نبي مرسل }
$$

"Aku memiliki waktu bersama Allah yang tidak dapat disusupi oleb malaikat terdekat atau seorang nabi yang membawa pesan sekalipun."

Jadi, ruh sholat itu bukan hanya dalam bentuk lahiriyah saja. Ruh shalat adalah ketenggelaman jiwa secara utuh dan ketidakhadiran tubuh, meninggalkan seluruh bentuk lahiriyah di luar. Tak ada sedikitpun ruang untuk siapapun, bahkan termasuk malaikat Jibril. Oleh karena itu, bagi Rumi, kita harus selalu merasa lemah dalam setia kondisi, meskipun kita dalam kondisi kuat. Sebab, di atas kekuatan masih ada kekuatan yang jauh lebih besar lagi. Hamba akan selalu berada di bawah kehendak Tuhan. Seorang hamba ibarat makhluk tanpa tangan, kaki, lunglai dan selalu membutuhkan Tuhan (Jalal al-Din Rumi, 2016, h. 44-47).

Rumi menjelaskan hadis tersebut secara tekstual sebagaimana yang terdapat di dalam lafadz hadis tersebut tanpa melakukan takwil meskipun ulama sufi dianggap lebih banyak melakukan takwil dalam melakukan interpretasi terhadap teks al-Qur'an dan Hadis. Rumi meyakini bahwa ada satu waktu ketika manusia memiliki hubungan intens dengan Tuhan dan tidak dapat disusupi oleh makhluk lain termasuk malaikat Jibril, yaitu pada saat shalat. Hal ini sebagaimana yang terdapat di dalam teks tanpa melakukan interpretasi lebih jauh. 


\section{Seorang mukmin adalah cermin bagi mukmin lainnya.}

Untuk membahas persoalan tersebut, Rumi mengutip hadis Nabi berikut:

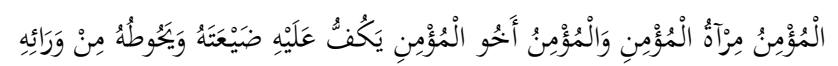

"seorang mukmin adalah cermin bagi mukmin lainnya dan seorang mukmin adalah saudara bagi mukmin lainnya. Dia tidak merusak, harta yang dimilikinya dan menjaga kepentingannya."

Hadis tersebut diriwayatkan oleh Abu Hurairah sebagaimana yang terdapat di dalam kitab sunan Abu Daud (Abu Daud,1998, h. 320-321). Selain itu, hadis tersebut juga diriwayatkan oleh Tabrani di dalam kitab alMu'jam al-Wasit dan juga oleh al-Baihaqi di dalam kitab al-Sunan al-Kubra. Menurut Zain al-Din Muhammad, hadis tersebut memberi gambaran bahwa bagi setiap mukmin itu seperti cermin. Jika seseorang ingin mengetahui perihal tentang dirinya, maka ia harus melihat temannya. Oleh karena itu, apabila dia melihat kebaikan dalam temannya, maka ia juga akan melihat kebaikan dalam dirinya, begitupun sebaliknya (Zain al-Din Muhammad, 1937, h. 252).

KH. A. Mustofa Bisri juga memiliki penafsiran yang sama. Menurutnya hadis tersebut memberi gambaran bahwa setiap mukmin itu bisa, atau seharusnya, menjadi cermin bagi mukmin lainnya. Seorang mukmin yang dapat menunjukkan noda saudaranya, agar saudaranya itu dapat menghilangkan noda bagi dirinya sendiri. Dengan kata lain, untuk dapat mengetahui aib yang ada pada diri kita sendiri, maka kita bisa bercermin dari saudara-saudara kita (KH. Mustofa Bisri, 2011, h. 18-19).

Rumi ketika memberikan gambaran dengan mengisahkan seekor gajah yang menuju sumber air untuk minum. Gajah itu kemudian melihat dirinya sendiri dari pantulan air dan kemudian melarikan diri karena menyangka ada gajah lain yang datang. Tanpa ia sadari ternyata yang dilihat ada dirinya sendiri. Begitupun dengan manusia yang merasa gelisah dan berusaha 
menghindar ketika melihat sifat buruk, seperti zalim, iri, dengki, serakah, keras hati, dan lain sebagainya, pada diri orang lain. akan tetapi, ketika sifat tersebut melekat pada dirinya, ia tidak merasakan apa-apa. Selama ada perasaan tersengat dan penyesalan dalam dirimu, berarti Tuhan masih memperhatikan dan mencintaimu. Jika kau melihat aib saudaramu, maka aib itu juga ada pada dirimu. Sebab, apa yang ada pada diri saudaramu yang membuatmu merasa jiiik juga ada pada dirimu (Jalal al-Din Rumi, 2016, h. $65)$.

Dalam menafsirkan hadis tersebut, Rumi memiliki pandangan yang sama dengan ulama pada umumnya bahwa manusia harus melihat kelebihan dan kekurangan orang lain untuk memperbaiki kelebihan dan kekuranga yang ada pada diri sendiri. Jika seseorang menjauhi orang lain karena sifat buruk, maka orang lain juga akan menjauhinya dengan sifat buruk yang sama, begitupun sebaliknya. Hanya saja, perbedaan Rumi dengan ulama lain dalam menjelaskan hadis tersebut terletak pada metode penafsiran. Rumi lebih banyak menggunakan perumpamaan atau kiasan untuk menjelaskan maksud yang ingin disampaikan. Hal tersebut dapat dipahami mengingat Rumi merupakan salah seorang sufi yang menganut aliran sastra sufi.

Bagi kalangan sufi, sastra merupakan salah satu media atau sarana yang digunakan untuk mengekspresikan perasaan, ide, nasehat, dan gagasan dalam bentuk puisi atau kisah-kisah yang mengandung hikmah. Atau dengan kata lain, sastra digunakan oleh para sufi untuk mengungkapkan pengalaman keruhanian mereka. Akan tetapi, mereka tidak pernah berniat untuk menjadi sastrawan atau penyair dengan karya-karya yang ditulis karena bagi mereka sastra merupakan salah satu seni yang bermutu tinggi, oleh karena itu dapat digunakan untuk membangunkan cinta yang telah tidur di dalam hati, baik cinta itu bersifat duniawi dan indrawi maupun cinta yang bersifat ketuhanan atau ruhaniyah (Abdul Hadi, 2001, h. 9). 


\section{Menyembunyikan hikmah dari orang-orang yang tidak layak} menerimanya.

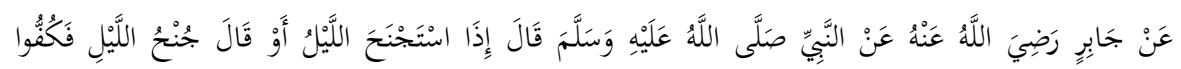

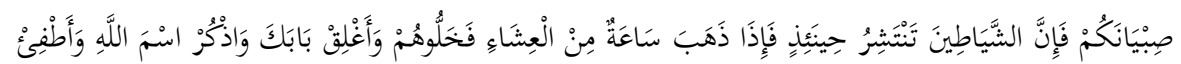

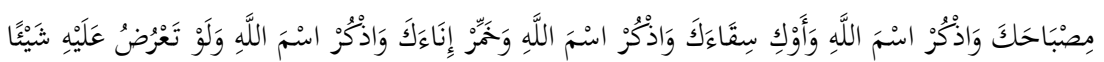

"Dirinyatkan dari Jabir r.a bahwa Nabi bersabda: Jika malam datang atau kalian berada di sore hari, maka tahanlah anak-anak kalian (di rumah), karena ketika itu setang sedang bertebaran. Jika telah berlalu sesaat dari waktu malam, maka biarkanlah mereka (jika ingin keluar). Tutuplah pintu dan ber₹ikirlah kepada Allah karena sesunggubnya setan tidak dapat membuka pintu yang tertutup. Tutup pula wadah minuman dan makanan kalian dan bervikirlah kepada Allah, walaupun dengan sekedar meletakean sesuatu di atasnya, matikanlab lampu kalian."(H.R Bukhari)

Hadis tersebut, dalam pandangan ulama hadis, berbicara tentang cara menghindari diri dari gangguan setan. Salah satuny adalah dengan menutup bejana atau wadah. Ibn Battal mengatakan bahwa menutup wadah dapat tercukupi meski hanya dengan menaruh sesuatu di atasnya untuk mencapai sunnah yang telah diajarkan oleh Nabi. Hal tersebut agar setan tidak mampu membukanya, atau dengan kata lain agar terhindar dari penyakit dan bala' yang sering muncul di malam hari (Ibn Battal Abu Hasan 'Ali bin Khalaf, 2003, h. 76). Muhammad Hasan Yusuf juga memiliki pandangan yang sama bahwa hadis tersebut menceritakan tentang adab sebelum tidur, salah satunya adalah menutup bejana. Hal tersebut bertujuan untuk menjaga dari setan karena setan tidak akan membuka ikatan penutup kantong air minum. Selain itu, juga menjaga dari penyakit yang turun pada malam hari, menjaga dari najis, kotoran, serangga, binatang, dan lain sebagainya (Muhammad Hasan Yusuf, 2008, h. 112).

Sedangkan dalam pandangan Rumi, hadis tersebut diucapkan Nabi ketika sekelompok orang munafik dan "orang asing" mendatangi Nabi. Mereka menceritakan sejumlah "rahasia" sambil memuji Nabi. Oleh karena 
itu, Nabi berkata kepada para sahabat untuk menutup wadah-wadah mereka. Hadis tersebut juga bukan sekedar anjuran dari Nabi agar para sahabat menutup semua mangkuk, cangkir, periuk, ceret, dan kendi-kendi mereka supaya terhindar dari kotororan yang dapat meracuni mereka. Akan tetapi, hadis tersebut mengisyaratkan bahwa Nabi ingin mengajak para sahabat untuk "menyembunyikan" hikmah dari orang-orang yang tidak layak untuk memperolehnya, yaitu orang-orang munafik yang senantiasa berdusta. Selain itu, Nabi juga mengajak para sahabat untuk menutup mulut mereka dan menunda lisan di hadapan "orang lain" karena mereka tidak layak untuk menerima hikmah dan kenikmatan ini. Dalam pandangan Rumi, keadaan para nabi, wali, dan umumnya manusia, yang baik maupun yang buruk, sesuai dengan tingkat esensi mereka masing-masing (Jalal al-Din Rumi, 2016, h. 145).

Hal tersebut diibaratkan dengan seorang gadis jelita yang menyerahkan dirinya kepada seseorang dan bersembunyi di rumahnya seraya berkata, “jangan perlihatkan aku kepada seorangpun karena aku hanya milikmu seorang," maka apakah boleh dan pantas bagimu untuk memamerkannya di pasar dan berkata kepada orang-orang,"kemarilah! Lihatlah gadis cantik ini." Jika kamu berbuat demikian, tentu gadis tersebut tidak akan dapat menerimanya. Oleh kerena itu, Rumi menganjurkan untuk tidak memberikan hikmah kepada orang yang tidak layak menerimanya karena dapat membuat hikmah tersebut menjadi salah makna. Begitupun larangan Rumi untuk tidak memberikan hikmah kepada orang yang berhak menerimanya karena akan membuat mereka salah arah (Jalal al-Din Rumi, 2016, h. 143).

Dalam tasawuf, Islam tidak hanya memiliki dimensi zahir (aspek luar) saja, akan tetapi juga memiliki dimensi batin. Sebagiamana yang terdapat di dalam Q.S al-Hadis: 3 bahwa Allah menjelaskan diri-Nya "Dialah Yang Awal dan Yang Akhir, Yang Zahir dan Yang Batin, dan Dia Maha Mengetahui 
segala sesuatu." Alam semesta merupakan manifestasi dari ilahi, sehingga apapun yang ada di dunia ini berasal dari-Nya. Jadi, apapun yang ada di alam tersebut memiliki sisi zahir dan sisi batin. Keduanya bukanlah sesuatu yang terpisah, melainkan sesuatu yang paralel dan tak terpisahkan. Sedangkan hikmah merupakan aspek batin dari sesuatu. Hikmah tersembunyi dari sesuatu yang nampak dan ia harus didekati dengan pendekatan batin yang memerlukan kesucian hati.

Oleh karena itu, Jalaluddin Rumi mengatakan bahwa hikmah hanya dapat diterima oleh orang-orang yang layak, yaitu orang-orang yang memiliki wadah yang suci, keluasan jiwa, dan pandangan yang luas, sehingga mereka tidak akan salah memaknainya. Begitupun sebaliknya, jika hikmah diberikan kepada orang-orang yang awam, maka mereka kan mempunyai peluang untuk salah memaknai hikmah tersebut.

\section{KESIMPULAN}

Kitab fibi ma fibi merupakan salah satu karya monumental dari Jalaluddin Rumi yang memuat tujuh puluh satu uraian untuk pendidikan ruhani manusia. Di dalam kitab tersebut Rumi menggunakan dalil-dalil yang berasal dari al-Qur'an maupun Hadis untuk mendukung penjelasan yang ia sampaikan. Jalaluddin Rumi dalam melakukan interpretasi teks hadis, sabagaimana para sufi lainnya, lebih cenderung melihat makna teks dari sudut pandang tasawuf yang dominan dalam mengandalkan intuisi dari hati yang suci. Meskipun demikian, interpretasi Rumi terhadap sebuah hadis tidak selamanya menyimpang jauh dari tekstual hadis, sebagaimana yang terlihat dari penjelasan sebelumnya. Rumi terkadang juga memaknai hadis secara tekstual sebagaimana yang dipahami oleh ulama lain. Perbedaan lain adalah dalam menyampaikan kandungan hadis, Rumi cenderung menggunakan bahasa sastra melalui puisi atau cerita-cerita. 


\section{DAFTAR PUSTAKA}

Ahmad, Khader, dkk (ed). 2017. Pengajian Sunnah Nabawiyah Metode dan Aliran. Kuala Lumpur: Universitas Malaya

Al-'Ayni, Mahmud bin Ahmad. t.t. Umdat al-Qari Sharah Sabih al-Bukhari. Kairo: Muhammad Amin Damaj

Al-'Akub, 'Isa 'Ali. 2002. Kitab Fihi ma Fihi. Shiria: Dar al-Fikr

Al-Ansari, Zakariyya ibn Muhammad. 1998. Fath al-Wahhab bi Sharh Minhaj alTullab. Bairut: Dar al-Kutub al-'Ilmiyyah

Al-Asqalani, Ibnu Hajar. 1991. Hadyu al-Sari Muqaddimah Fath al-Bari. Beirut: Dar al-Fikr

Al-Ash'ath, Abu Daud Sulaiman bin. 1998. Sunan Abi Dand. Beirut: Muassasah al-Riyan

A. E. Afifi. 1995. Filsafat Mistis Ibn 'Arabi. Jakarta: Gaya Media Pratama

Bisri, KH. Mustofa. 2011. Membuka Pintu Langit. Jakarta: Kompas

Al-Bukhari, Abu 'Abdillah Muhammad bin Isma'il. 2002. Sabih al-Bukhari. Beirut: Dar ibn Kathir

Al-Hakim, Muhammad bin 'Abdullah. 1977. Kitab Ma'rifah Ulum al-Hadis. Beirut: Dar al-Kutub al-'Ilmiyyah

Al-Hafani, 'Abd al-Mun'im. 1987. Mu'jam Mustalah at al-Sufiyyah. Beirut: Dar al-Masirah

Hadi, Abdul. 2001. Tasawufyang Tertindas. Jakarta: Paramadina

Ibn Manzhur, Muhammad bin Muhammad al-Ifriqi al-Misri. 1994. Lisan al'Arab. Beirut: Dar al-Fikr

Ibn al-Salah, Abu 'Amru Uthman bin 'Abd al-Rahman al-Shahrazwari. 1989. Muqaddimah Ibn al-Salah fi Ulum al-Hadith. Beirut: Dar al-Kutub al'Ilmiyyah

'Itr, Nur al-Din. 1979. Manhaj al-Naqd fi 'Ulum al-Hadith. Beirut: Dar al-Fikr Isma'il, Tahsin 'Abd al-Jabbar. 2013. Mukhtarat min Qasaid Jalal al-Din al-Rumi. Dubai: Bahr al-Kutub 
Al-Khatib, Muhammad 'Ajjaj. 2009. Usul al-Hadis (Beirut: Dar al-Fikr

Kafafi, Muhammad 'Abd al-Salam. 1966. Masnawi. Beirut: Al-Maktabah alMisriyyah

Khalaf, Ibn Battal Abu Hasan 'Ali bin. 2003. Sharh Sabih al-Bukhari li Ibn Battal. Riyad: Maktabah al-Rashad

Ketz, Steven T. 2000. Mysticism and Sacred Scripture. Oxford: Oxford University Press

Muhammad, Zain al-Din. 1937 H. Faid al-Qadir Sharh Jam'u al-Sagir. Mesir: Maktabah al-Tijariyyah al-Kubra

Munawwir, Ahmad Warson. 1997. al-Munawnir: Kamus Arab Indonesia. Surabaya: Pustaka Progressif

Al-Nadwi, Abu al-Hasan. 2018. Jalaluddin al-Rumi. Kairo: Tanwir li al-Nashri wa al-I'lam

Nasution, Harun. 1973. Filsafat dan Mistisime dalam Islam. Jakarta: Bulan Bintang

Nicholson, Rein old A. 2017. Masnawi Senandung Cinta Abadi. terj. Abdul Wahid. Yogyakarta: IRCisSoD

Al-Qattan, Manna'. 2000. Mabahis fi Ulum al-Qur'an. Mesir: Maktabah Wahbah

Al-Qardawi, Yusuf. 1991. Kaifa Nata'amal Ma'a Al-Sunnah Al-Nabawiyyah. Kairo: Maktabah Wahbah

Rizal, Ikhwan Fauzi. 1996. Pemikiran Sufi di bawah Bayang-bayang Fatamorgana. Jakarta: Amzah

Rumi, Jalal al-Din. 2016. Fibi ma Fibi, terj. Abu Ali dan Taufiq Damas. Jakarta: Zaman

Schimmel, Annemarie. 1993. The Triumphal Sun: A Study of the Works of Jalaluddin Rumi. New York: State University of New York Press

Sultan, Nur al-Din 'Ali bin Muh\}ammad bin. 1987. al-Asrar al-Marfu'ah fi alAkhbar al-Maudu’. Bairut: al-Maktabah al-Islami 
Sya'roni, Usman. 2008. Otentisitas Hadis Menurut Abli Hadis dan Kaum Sufi. Jakarta: Pustaka Firdaus

Tahan, Mahmud. t.th. Taisir Mustalah al-Hadis. Mesir: Markaz al-Hadani li alDirasat

Al-Turmusi, Muhammad Mahfuz bin Abdillah. 1974. Manhaj Dhawi al-Nazar. Surabaya: Sirkah Maktabah Ahmad bin Sa'ad bin Nabhan

Ushama, H Thameem. 2000. Metodologi Tafsir al-Qur'an, terj. Hasan Basri dan Amroeni. Jakarta: Riora Cipta

Al-Walatturi, Abu Muhammad. 1997. Ibtigha' al-Wusul li Hubb Allab wa Madh al-Rasul. Turki: Maktabah al-Haqiqah

Yusuf, Muhammad Hasan. 2008. Resep Tidur ala Nabi, terj. Muhammad bin Ibrahim. Solo: Qoula

Al-Zahabi, Muhammad Husain. t.th. Tafsir wa al-Mufassirun. Mesir: Dar alKutub al-Hadisah

Al-Zarqani, Muhammad 'Abd al-'Adzim. t.tp. Mana bil al-Irfan fi 'Ulum alQur'an. Kairo: Matba'ah 'Isa al-Babi al-Halabi wa Shurukauh 